\title{
La cortesía y los roles trampa para la mujer líder dentro del foro parlamentario andaluz*
}

AURELIA CARRANZA MÁRQUEZ

UNED

ABSTRACT: In this work we analyse different discourse strategies used by female leaders in the Andalusian Parliament applying the concept of role traps. Such roles were initially described from a social perspective and within a corporative context (Kanter, 1977). Currently, these roles have been reinterpreted from a sociolinguistic approach (Baxter, 2012) and are approached as strategic and dynamic discourse resources. We will focus on the specific roles of «mother» and «pet», which will be studied as discourse strategies related to politeness in an attempt to determine whether they convey the feminization of language within the frame of the Andalusian Parliament.

Keywords: politeness, Andalusian Parliament, gender, role traps, female leader.

RESUMEN: En el presente estudio se analizan diferentes estrategias discursivas empleadas por consejeras del Parlamento Andaluz aplicando el concepto de roles-trampa. Estos roles se describieron inicialmente desde una perspectiva meramente social en un contexto corporativo (Kanter, 1977). Más recientemente Baxter los reinterpreta desde una perspectiva socio-lingüística (2012), contemplándolos como recursos discursivos estratégicos y dinámicos que vamos a visualizar dentro del foro parlamentario andaluz. Nos centraremos en los roles específicos de «madre» y «mascota», interpretándolos como estrategias discursivas ligadas a la cortesía, a fin de poder detectar si los mismos derivan en una feminización del lenguaje dentro del marco a analizar.

Palabras clave: cortesía, Parlamento Andaluz, género, roles trampa, mujer líder.

* Esta investigación se inserta dentro del Proyecto de investigación de Excelencia «La perspectiva de género en el lenguaje parlamentario andaluz», financiado por la Junta de Andalucía (2011-2014) y cofinanciado con fondos FEDER y del Proyecto FunDETT (FFI200907308 - subprograma FILO). 


\section{Introducción}

Hasta la fecha se han realizado diferentes estudios sobre el lenguaje de la mujer en diferentes contextos socio-culturales en un intento por identificar los diferentes factores lingüísticos que las han tenido relegadas a un segundo plano social (Lakoff, 1973, 1975; APUD, 1998; Holmes, 2006, etc.). Esta premisa supone una relación directa causa-efecto entre el lenguaje de la mujer y su acceso a las posiciones de poder dentro de las diferentes esferas sociales. A día de hoy no se ha podido establecer una conexión clara y directa entre su participación en la esfera pública y el lenguaje que típicamente se les atribuye.

Este trabajo no pretende dilucidar la relación causa-efecto, es decir el por $q u e ́$, sino más bien analizar el cómo. Se centra en cómo utilizan el lenguaje las mujeres que han alcanzado un estatus de poder desde la reinterpretación de los roles atribuidos típicamente a la mujer líder y que alimentan un tira y afloja con sus interlocutores masculinos en un intento por controlar el equilibrio de poderes dentro de un contexto determinado, en este caso, del foro parlamentario andaluz.

Ya en los años setenta se describieron una serie de roles en los que se encasillaba a las mujeres líderes en el campo empresarial, a fin de acomodarlas a algún arquetipo anterior que diera sentido al avance de la mujer en una sociedad acostumbrada a que el liderazgo social fuese un club exclusivamente masculino (Kanter, 1977). Ante la nueva situación que surgía, mujeres liderando a hombres, la respuesta social fue identificarlas con roles preexistentes de mujer con cierta autoridad, aunque en algunos casos de dudosa autoridad, dentro de la familia y la sociedad en general. Estos roles eran: dama de hierro, seductora, madre y mascota (en adelante rol $\mathrm{DH}$, rol SD, rol MD y rol MS).

Estos roles en sí son interesantes pero no aportan nada concreto en un ámbito lingüístico. Esta dimensión, de mayor interés para este estudio, se solapa posteriormente cuando Baxter (2012) los reinterpreta desde un punto de vista sociolingüístico, contemplándolos como estrategias discursivas dinámicas empleadas en función del contexto, los interlocutores y los objetivos del hablante. Es dentro de este marco donde encuadramos nuestro trabajo, pues nos permitirá analizar las diferentes estrategias discursivas empleadas por diferentes consejeras del Parlamento Andaluz a través de constructos sociales que engloban factores lingüísticos, discursivos y sociales. Igualmente, intentaremos discernir si el uso de estos roles supone una feminización en el lenguaje de las líderes (consejeras) dentro de un foro profesional con marcado estilo propio. Por feminización del lenguaje entendemos que el lenguaje se adapta a las características del lenguaje femenino descritas por diferentes autores (Lakoff, 1975; Kramarae, 1981; Cameron, 1985, 1990; Tannen, 1990, 1994; Coates, 1989; Lozano, 1995; etc.), 
los cuales defienden que se trata de un lenguaje más colaborativo e indirecto que el del hombre.

Tanto Kanter como posteriormente Baxter se centraron en un contexto corporativo, sin embargo, creemos que sus premisas son aplicables a la esfera política, pues como explicaremos después, en ambos casos se trata de comunidades de práctica, y desde un punto de vista social, es en la esfera política donde se ha llevado a cabo un esfuerzo mayor en la equiparación entre hombres y mujeres en cargos de responsabilidad, lo que supone un campo especialmente fértil donde pilotar, desde un punto de vista teórico, el valor discursivo de los constructos sociales anteriormente citados.

Para ello se han analizado diez comparecencias y diez preguntas orales a tres consejeras diferentes del Parlamento Andaluz desde mayo de 2010 a marzo de 2011. Intervienen en las mismas la Sra. Aguilera García, Consejera de Agricultura y Pesca; la Sra. Navarro Garzón, Consejera para la Igualdad y Bienestar Social; y la Sra. Montero cuadrado, Consejera de Salud.

\section{Marco teórico}

A continuación procedemos a desarrollar el ámbito teórico sobre el que pivotará este trabajo, donde se discutirá el discurso parlamentario como comunidad de práctica y se relacionarán conceptos como lenguaje y género desde la perspectiva de los roles trampa, los cuales se entienden dentro del siguiente contexto: «[situations when] the characteristics of tokens as individuals are [...] distorted to fit pre-existing generalizations about their category as a group» (Kanter, 1993: 230) [situaciones en las que las características de los símbolos que se asocian a individuos son (...) distorsionadas para encarnar generalizaciones preexistentes sobre su condición como representante de un grupo]. ${ }^{1}$

\subsection{El discurso parlamentario como comunidad de práctica}

Hemos considerado oportuno aplicar las premisas lingüísticas de estos estudios sobre el mundo corporativo al ámbito del discurso político, pues en ambos casos se trata de comunidades de práctica (CdP). El concepto de CdP fue introducido en la investigación del lenguaje y el género por Eckert y McConnellGinet en 1992, quienes siguiendo a Lave y Wenger (1991) lo describen como un conjunto de personas que acometen una tarea común, y el desarrollo de dicha

1. Mi traducción. 
tarea conlleva una manera determinada de hacer las cosas, prácticas discursivas comunes y específicas de la praxis que se lleva a cabo, creencias, valores y relaciones de poder (Eckert y McConnell-Ginet,1992: 464).

La noción de CdP puede aportar un marco para analizar la complejidad y juzgar una declaración como cortés o descortés (Litosseliti y Sunderland, eds., 2002), aunque en primer lugar habría que hacer una distinción entre lo (des)cortés y lo político (polite vs. politic, Watts, 1992). Christie, siguiendo el planteamiento inicial de Watts (2002: 8), describe estos conceptos de la siguiente manera: «El comportamiento político se explica como una decisión activa de amoldarse y trabajar dentro de unas limitaciones estructurales [...] El comportamiento cortés es lo que está socialmente marcado por la comunidad de práctica como más que político». Es decir, en un contexto donde la descortesía es práctica común hasta el punto de poder ser considerada como la manera acostumbrada de comunicación entre sus miembros, el ser descortés sería un comportamiento político, pues es lo esperado. Y al contrario, si en este mismo contexto un interlocutor es cortés, se entenderá que va más allá de lo político y su comportamiento es puramente cortés.

La primera pregunta que se nos plantea es: ¿pueden ser consideradas las sesiones de la Junta de Andalucía como la producción discursiva de una CdP? Gracias a Wenger (1998) esta pregunta tiene una respuesta clara, pues de las catorce condiciones que describió para que una comunidad de hablantes pueda ser considerada una CdP el foro analizado cumple doce. Quedan sin cumplir la número cuatro, «ausencia de preámbulos», como si las conversaciones e interacciones fuesen una mera continuación de un proceso en marcha; y la cinco, «presentación rápida de un problema para ser discutido». Y aun así, se puede considerar que estas características discordantes forman parte de los rituales discursivos del grupo, pues existe un protocolo fijo en lo que a las intervenciones se refiere que va más allá de elecciones personales de los individuos que participan del foro. Dentro de las condiciones que sí se cumplen encontramos: «relaciones sostenidas en el tiempo (de armonía o conflicto), formas comunes de acometer tareas juntos, la habilidad para evaluar si ciertas acciones o producciones son apropiadas, una jerga común, estilos reconocibles que acentúan la pertenencia a la comunidad», etc.

\subsection{Lenguaje y género}

Hace cuatro décadas la mujer apenas tenía acceso a puestos de relevancia en el mundo empresarial. En este contexto Rosabeth Kanter (1977), profesora de la Facultad de Economía de la Universidad de Harvad, analizó el liderazgo femenino dentro del contexto corporativo. Para ello describió cuatro roles-trampa en 
los que las mujeres se veían obligadas a acomodarse cuando adquirían puestos de responsabilidad en corporaciones, generalmente dominadas por hombres, para ser aceptadas en su entorno. Estos roles suponen la encapsulación de la mujer dentro de ciertas categorías basadas en arquetipos históricos y familiares. Estos validaban una serie de posiciones de liderazgo aceptadas por una sociedad predominantemente patriarcal aunque, por otra parte, al reducir a la profesional a una serie de categorías de género, se minaba la percepción de su valía profesional obstaculizando su progresión a nivel laboral, de ahí su definición como trampa. Según Kanter, estos roles eran los siguientes: dama de hierro, madre, mascota y seductora.

El rol DH es el que más autoridad desprende e implica una masculinización de la mujer, pues muestra una agresividad generalmente atribuida a los hombres. $\mathrm{Su}$ relación con los subordinados es tensa, pues la ven como a una persona dura e incluso amenazante.

El rol MD, que de por sí implica cierta autoridad, es un rol basado en aspectos socio-emocionales más que en aspectos profesionales. Estas profesionales se comportarían de manera más cercana y reforzarían la moral del grupo reconfortando y cuidando a sus miembros. El inconveniente de este rol es que este comportamiento se espera entre iguales, lo que supone un obstáculo para acceder a puestos de gran responsabilidad.

El rol MS conlleva muy poca autoridad. La profesional que adopta este rol es vista como una chiquilla inmadura que interpretaría el ser el foco de las bromas de los compañeros como una forma de ser aceptada en el grupo. La simpatía del grupo hacia ella se ve oscurecida por la falta de madurez que se le presume, lo cual no ayuda en absoluto a su ascensión en la jerarquía de la corporación.

Finalmente, el rol SD encasilla a la profesional en la posición de objeto sexual. Usa sus armas de mujer para seducir y así conseguir sus objetivos. De esta manera, su valía profesional queda totalmente fuera de la fórmula, pues sus logros se atribuyen exclusivamente a sus artes de seducción.

El estudio de Kanter tiene poco alcance para nuestro trabajo pues, aunque es muy interesante y fue muy novedoso en su tiempo (1977) en lo que a los estudios de género y a la administración de empresas se refiere, no prestó mayor atención a los factores lingüísticos que dichos roles podrían implicar y, precisamente, son estos los factores que más nos interesan.

Esta teoría ha sido recientemente revisada y actualizada por Judith Baxter (2012: 82) desde una perspectiva socio-lingüística. Esta autora reformula los roles-trampa desde un punto de vista del constructivismo social, pues contempla el uso del lenguaje como un constituyente social y discursivo de la identidad de las personas. En este sentido, va más allá de los roles como modelo estático de comportamiento y los reinterpreta como estrategias discursivas dinámicas, ya que 
pueden ser usadas indistintamente por una misma hablante con el fin de obtener unos resultados o efectos específicos entre sus interlocutores.

En cualquier caso, en ninguno de estos trabajos se aporta descripción alguna sobre el impacto que el uso de estos roles tendría en el lenguaje de las líderes cuando se comunican con los miembros de su grupo. Igualmente, tampoco se presentan patrones de comportamiento dentro de colectivos específicos. Grosso modo, y a fin de tener ciertos fundamentos lingüísticos a la hora de detectar y analizar los diferentes roles que adoptan los hablantes, definiremos una serie de comportamientos lingüísticos y discursivos que se podrían asociar a estos roles por afinidad con el perfil de los mismos. Pero antes habría que especificar el enfoque discursivo del que partimos.

En concreto vamos a partir de la teoría de la cortesía, cuyos conceptos básicos tomaremos de Brown y Levinson (1987). Para ellos la cortesía lingüística es un mensaje adicional que se está comunicando. Por ejemplo, la frase «I would really appreciate it if you lend me your car» [estaría muy agradecido si me prestases tu coche], está comunicando dos cosas: (a) una petición y (b) que intenta ser cortés.

Según estos autores, toda «Persona Modelo» tendrá dos cualidades principales: «racionalidad e imagen» (1987: 58).

By «rationality» we mean something very specific -the availability to our MP [Model Person] of a precisely definable mode of reasoning from ends to the means that will achieve those ends. By «face» we mean something quite specific again: our MP is endowed with two particular wants- roughly, the want to be unimpeded and the want to be approved of in certain respects.

[Por «racionalidad» queremos decir algo muy específico - la capacidad de nuestra persona modelo para un tipo de razonamiento determinado que va desde la consecución del fin a los medios empleados para ello. Con «imagen» nos referimos de nuevo a algo muy específico: nuestra persona modelo tiene dos necesidades- básicamente, la necesidad de que no se le impida nada y la necesidad de aprobación en ciertos aspectos. $]^{2}$

Se basan en los conceptos de imagen y autoestima de Goffman (1967), «face, the public self-image that every member [of a society] wants to claim for himself» y definen dos tipos de imagen (Brown y Levinson, 1987: 62):

NEGATIVE FACE: The want of every «competent adult member» that his action be unimpeded by others.

2. Mi traducción. 
POSITIVE FACE: The want of every member that his wants be desirable to at least some others.

[IMAGEN NEGATIVA: La necesidad de cada «miembro adulto competente» de que los demás no impidan sus acciones.

IMAGEN POSITIVA: La necesidad de cada miembro de que sus intenciones sean deseables al menos para alguien.] $]^{3}$

La imagen es vulnerable y lo que se considera normal en una interacción es mantener la imagen de nuestro interlocutor, y para ello los hablantes pueden usar estrategias lingüísticas conformes con los principios de cortesía y que servirían para comunicar los mensajes y la intención de ser cortés.

Leech (1983) mantenía que había actos que eran inherentemente corteses o descorteses; Brown y Levinson (1987: 62) sostienen que hay ciertos actos que son inherentemente amenazantes para la imagen (face-threatening acts). Hay tres variables que determinan la gravedad de un acto de amenaza a la imagen: (a) la distancia social entre el hablante y el oyente ( $\mathrm{D}=$ distancia social), (b) el poder relativo del hablante sobre el oyente $(\mathrm{P}=$ poder relativo) y $(c)$ el grado de imposición del acto en una cultura determinada $(\mathrm{R}=$ rango absoluto).

Este modelo, sin embargo, tiene sus detractores, quienes lo encuentran insuficiente y demasiado rígido en algunos aspectos. Un autor que aporta una visión diferente de la cortesía es Fraser (1990), que la denomina visión conversacionalcontractual.

El modelo de Fraser difiere fundamentalmente del modelo de Brown y Levinson en que tiene una visón dinámica en la que los interlocutores reconocen "some initial set of rights and obligations that will determine [...] what the participants can expect from the other(s)» (Fraser, 1990: 232) [un conjunto inicial de derechos y obligaciones que determinarán $[\ldots]$ lo que los participantes pueden esperar de los demás]. ${ }^{4}$ Si hay un cambio en el contexto durante la conversación, el «contrato conversacional» siempre puede ser renegociado.

Fraser observa que algunos términos del contrato vienen impuestos por la convención, los turnos de habla, el uso de un lenguaje inteligible, etc. Otros vienen impuestos por las instituciones sociales en las que tiene lugar la interacción, como por ejemplo, el hecho de que no se debe hablar en voz alta durante un servicio religioso. Y finalmente, otras dependen de las características particulares de la situación en la que ocurre la interacción: la relación de poder entre los hablantes es muy importante.

El modelo de Fraser es más flexible y reconoce el carácter cambiante de las diferentes situaciones sociales. Todo se negocia contextualmente:

3. Mi traducción.

4. Mi traducción. 
What we view as polite or impolite behavior in normal interaction is subject to immediate and unique contextually-negociated factors, and as such, cannot be codified in any interesting way. The normative perspective must be rejected. (Fraser, 1990: 234)

[Lo que percibimos como comportamiento cortés o descortés en una interacción normal está sujeto a una serie de factores directos y singulares que son negociados contextualmente, y como tales, no se pueden codificar de una manera interesante. La perspectiva normativa debe ser descartada. $]^{5}$

Este modelo más dinámico y flexible se acomoda mejor en nuestro estudio, pues partimos de la premisa de que los roles trampa son una estrategia discursiva dinámica.

Para poder avanzar procedemos a describir los diferentes roles trampa desde una perspectiva discursiva y lingüística. Estas descripciones parten de una serie de supuestos predecibles dentro del perfil de cada uno de ellos y son relevantes de cara al posterior análisis, para el que se precisa una serie de parámetros claros a la hora de detectar los diferentes roles empleados por las consejeras.

DH:

A nivel discursivo se podría esperar una evaluación negativa del oponente en caso de conflicto, ataques a la imagen, ironía, y en general un lenguaje directo, asertivo y poco atenuado, si bien la conformidad con sus planteamientos sería bien recibida.

A nivel lingüístico esto se podría traducir en el uso de adjetivos y formulaciones extremas, preferencia por la modalidad deóntica y axiológica, repeticiones, etc.

No hay ningún estudio que relacione estructuras lingüísticas determinadas con ningún rol determinado pero en cualquier caso pensamos que estos supuestos no desentonan con el valor discursivo que contienen los diferentes roles trampa.

MD:

A nivel discursivo se busca salvar la imagen del contrincante en un ambiente de integración y de creación de grupo, así como el refuerzo de los lazos de soli-

5. Mi traducción. 
daridad. En este caso primaría la evaluación positiva en relación a los miembros del grupo.

A nivel lingüístico se podría esperar una preferencia por la modalidad epistémica, el uso de atenuantes (diminutivos, partitivos, etc.), así como el uso inclusivo del pronombre nosotros.

MS:

Nivel discursivo; lenguaje atenuado. Se intenta salvar la imagen del otro en un esfuerzo por ser aceptada por el grupo. Se evitan los conflictos y confrontaciones directas, y si se producen, es en tono humorístico, para quitar importancia al asunto.

Nivel lingüístico; preferencia por la modalidad epistémica, uso de atenuantes.

Cabe resaltar que no se han encontrado casos de consejeras dentro de este rol carente de autoridad, lo cual concuerda con lo esperable en una figura que ha llegado a un puesto de responsabilidad tal como es la dirección de una Consejería. Lo que sí se ha podido observar son alusiones, en algunos casos en clave de humor, de los miembros de los grupos de la oposición a comportamientos profesionalmente inmaduros de las consejeras, pero al contrario de lo que se espera de una mascota, estos comentarios no se aceptan con humor y buena disposición sino que son inmediatamente rebatidos.

SD:

El rol SD es un poco complejo de describir a nivel lingüístico, pues está definido a través de parámetros de actuación en relación, no solo a personas del grupo, sino también a personas ajenas al grupo que se lidera, en concreto, a las personas que están por encima del grupo en sí y con capacidad de decisión sobre quién debe liderarlo. Este rol viene definido por la manera en que se ha accedido al cargo que se desempeña y no solo por cómo el líder interactúa con los miembros de su grupo. En cualquier caso, en términos generales, se podría esperar una actitud negativa del resto del grupo por considerar que su líder ha alcanzado su estatus por motivos ajenos a su valía profesional. Esto podría provocar un discurso a la defensiva por parte de la seductora, lo que la acercaría a la dama de hierro, aunque esto dependería en gran medida de la personalidad de la jefa de grupo.

Habría que destacar que en nuestro corpus este rol no ha sido detectado, pues iría en contra del hablante. En España se ha hecho un gran esfuerzo y se 
pone mucho énfasis en evitar que la mujer sea presentada como un objeto sexual, especialmente dentro de las instituciones. Dentro del foro parlamentario andaluz este rol, hoy por hoy, es muy difícil de encontrar, tanto por parte de las consejeras como por parte del resto de los miembros del Parlamento. Cualquier alusión sexual en relación a una mujer, independientemente del puesto que ocupe en la jerarquía política, es duramente criticado y aporta un descrédito que difícilmente ningún grupo político estaría dispuesto a afrontar.

También es importante destacar que los roles anteriormente citados pueden ser asumidos por el hablante, o no, en función de los intereses del mismo, es decir, una mujer puede hacer uso de un rol específico con un fin determinado o, al contrario, sus interlocutores pueden asignarle dichos roles, los cuales pueden ser confirmados o rechazados por parte de la hablante.

La mujer aún no ha superado todas las barreras en lo que al acceso a puestos de mayor responsabilidad se refiere. Los valores atribuidos a los líderes siguen siendo en cierto sentido masculinos, es decir, unos valores relacionados con un estilo directo y agresivo (Cameron, 2006; Holmes, 2006; Schnurr, 2009). La mujer que se aleja de la norma pierde enteros en lo que a la percepción de su profesionalidad y nivel de competencia se refiere (Priora y Brannen, 2009). Holmes (2006) describe esta situación a través del concepto de la «doble atadura», pues para la mujer líder, o aspirante a serlo, es difícil encontrar el equilibrio que le evitaría ser considerada o demasiado enérgica o demasiado indecisa.

El foro de nuestro estudio es quizás una excepción, pues la paridad en el ámbito político ha sido, en los últimos años, un símbolo de la mentalidad progresista de los diferentes partidos. En el Parlamento Andaluz encontramos tanto consejeros como consejeras que serían el equivalente del líder corporativo.

\section{Metodología}

Antes de comenzar el análisis es imprescindible hacer una serie de matizaciones. Por un lado, en los debates estudiados los diferentes representantes de los grupos parlamentarios no suponen la única audiencia del intercambio. Los votantes y simpatizantes de los mismos tienen un gran peso en la batalla dialéctica que se desata en las diferentes intervenciones de los representantes de los distintos grupos parlamentarios. Se trata de una batalla entre subgrupos dentro de un foro específico que conforma una comunidad de práctica en la que el conflicto es un comportamiento político y donde los diferentes subgrupos luchan por mantener una imagen positiva y de autoridad frente a la opinión pública, al mismo tiempo que la de los oponentes es denostada. A nivel político es un comportamiento esperado y aplaudido por los seguidores de los subgrupos, quienes esperan una batalla dialéctica en la que sus representantes salgan victoriosos. 
Por otro lado, no hay que perder de vista que los comportamientos están principalmente motivados no por los individuos en sí, sino por su pertenencia a determinados grupos parlamentarios que funcionarían como entes homogeneizadores. Es decir, la motivación del uso de estas estrategias está determinada en gran medida por el conflicto entre partidos. Esto queda patente de forma explícita en el siguiente ejemplo, donde la Sra. Consejera de Salud se dirige en los siguientes términos a la Sra. Isac García, diputada del PP: «que no se lo digo a Usted, se lo digo a su formación» (8-10/APC-000378, pág. 21).

En nuestro análisis nos hemos centrado en los roles MD y MS y hemos descartado los roles DH y SD. El primero porque en el foro parlamentario andaluz este rol se da por sentado, es decir, es político, pues el lenguaje de las representantes del sexo femenino no solo se ha adaptado al estilo típicamente masculino del entorno (Wenger, 1998: 126) sino que es más tajante y agresivo que el empleado por los consejeros y diputados (Brenes, 2012: 70). Este fenómeno se debe a que «la mujer, como hablante competente, ha adaptado su discurso a todos los factores que dibujan la situación comunicativa, y no solo a su género» (Brenes, 2012: 70). Esto no implica que dentro de este rol no se puedan apreciar diferencias en relación al lenguaje masculino pero, en cualquier caso, lo que intentamos dilucidar es si estos roles tienen un valor discursivo real; y para ello un rol que conlleva la masculinización de la mujer nos parece de menor interés que aquellos que se ajustan a parámetros tradicionalmente considerados típicamente femeninos (lenguaje colaborativo e indirecto).

El rol SD, por su parte, ha sido descartado pues el contexto social y político en España actualmente está muy sensibilizado con la importancia de la presencia de la mujer en las diferentes esferas e instituciones y cualquier alusión a las mismas como objetos sexuales supondría un descrédito para el grupo político que lo plantease.

Dentro del contexto descrito, el uso del rol MD a priori sería cortés, por lo que su empleo, en principio, podría matizar el marcado estilo masculino empleado en el foro. El rol MS, con la merma de autoridad que conlleva, puede arrojar luz sobre cómo las representantes parlamentarias defienden su estatus frente a los ataques a su autoridad por parte de los grupos oponentes. En este sentido, el uso de estos roles puede tener mucho que aportar al lenguaje de las consejeras, lo que nos permite preguntarnos: ¿sirven como elementos feminizantes del lenguaje? o por el contrario ¿sirven como una herramienta más puesta a disposición del estilo agresivo dominante en el foro de nuestro estudio? Y en este caso, ¿cómo se llevaría a cabo?

Las Consejerías estudiadas han sido las de Salud (Sra. Montero), Igualdad y Bienestar Social (Sra. Navarro) y Agricultura y Pesca (Sra. Aguilera) en los años 2010 y 2011. Se han analizado diez comparecencias y diez preguntas orales en 
un intento por analizar el discurso de las consejeras en situaciones con diferentes grados de espontaneidad. ${ }^{6}$

Para poder contestar las preguntas planteadas anteriormente, nos ha parecido importante contar con una muestra de control que nos sirva para comprobar si los roles analizados son también empleados por los líderes masculinos (consejeros). Esto sin duda nos ayudaría a calibrar la validez de estos roles dentro del análisis del discurso.

Se han analizado cinco comparecencias y ocho preguntas orales en las que participaban los consejeros de Economía, Innovación y Ciencia (Sr. Ávila Cano) y de Educación (Sr. Álvarez de la Chica) en los períodos comprendidos entre el 7 de octubre de 2010 y 24 de marzo de 2011.

La descripción discursiva y lingüística aportada de los diferentes roles servirá para detectar los mismos dentro de nuestro corpus. Dichas descripciones son supuestos orientados a facilitar el análisis y en ningún caso están basados en estudios cuantitativos o cualitativos. Son una mera orientación dentro de unos parámetros que podrían encajar dentro de lo esperable en cada caso.

Hemos procedido al análisis del corpus centrándonos en los intercambios de los miembros del Parlamento Andaluz con las consejeras y consejeros seleccionados teniendo en cuenta las estrategias de imagen empleadas y sus efectos discursivos en el intercambio. Dichas estrategias se han contemplado como recursos específicos de los diferentes roles descritos anteriormente.

\section{Análisis}

Comenzaremos con los resultados del análisis del uso del rol MD por parte de las consejeras. El contenido de este rol varía mucho en función del receptor a quien va dirigido. En relación al propio partido funciona de forma genuina, es decir, enfatiza los aspectos positivos de los miembros de su grupo. En relación a los partidos de la oposición, generalmente tiene alguna otra intención encubierta que este rol suaviza o enfatiza.

6. Las comparecencias analizadas son las siguientes: 8-10/APC-000236, 8-10/APC-000246, 8-10/APC-000272, 8-10/APC-000279, 8-10/APC-000337, 8-10/APC-000855, 8-10/APC00081, 8-10/APC-000146, 8-10/APC-000470, 8-10/APC-000689, 8-10/APC-000319. Las preguntas orales analizadas son: 8-10/POC-000153, 8-10/POC-000515, 8-10/POC-000440, 8-10/POC-000553，8-10/POC-000684，8-10/POC-000828，8-10/POC-000020，8-10/POC000422, 8-10/POC-000920, 8-10/POC-000180. 
Se han detectado dos usos concretos en este sentido: (1) intensificador/atenuante en un acto de amenaza a la imagen del oponente, y (2) refuerzo del grupo parlamentario del hablante en contraste con el del oponente.

\subsection{Intensificador/atenuante en un acto de amenaza a la imagen del oponente}

\subsubsection{Intensificador}

En algunos casos encontramos estrategias de solidaridad con el hablante destinadas a crear un terreno común para seguidamente contradecir las bases establecidas y atacar la imagen del contrario. Esto supone un contrapunto y una rotura del clímax que enfatiza la agresión por el contraste creado. En el siguiente ejemplo, la Consejera de Agricultura y Pesca interviene en contestación al Sr. Armijo del Partido Popular en relación a la campaña de recogida de aceituna 2009-2010:

(1) Consejera: Usted se ha referido a medias de precios, y no sé si está hablando de la campaña 2008-2009, a la que se ha referido, o la última, 2009-2010 [...] Sr. Armijo, usted ha empezado diciendo que su comparecencia tiene un espíritu constructivo -y yo así lo creo- lo que pasa es que tengo que decirle, en principio, que ahí tiene algunas pequeñas confusiones, seguramente involuntarias, pero que yo voy a ver si podemos aclararlas en las diversas intervenciones que tenemos todavía. ' (8-10/APC-000146, pág. 10)

En esta intervención la consejera parte estableciendo un punto de encuentro, dando credibilidad al oponente en su intención de hacer una crítica constructiva, para seguidamente aportar el contrapunto. Este contrapunto está basado en el argumento de la confusión, es decir, se da por sentado que el oponente, en principio, no ha alcanzado a comprender algunos datos. Esto se hace a través de estrategias típicas del rol MD, es decir, de forma atenuada salvaguardando la imagen positiva del interlocutor, aunque llama la atención el énfasis con el que se lleva a cabo, con un adjetivo minimizador, «pequeñas confusiones», un juicio de valor, «seguramente involuntarias», el uso inclusivo del pronombre nosotros, «a ver si podemos aclararlas». Se podría pensar que todo este despliegue de recursos atenuantes tiene como fin minimizar el ataque a la imagen del oponente en relación a un malentendido

7. El énfasis es mío. A partir de ahora todas las cursivas en los ejemplos aportados se entenderán como énfasis por parte de la autora. 
con los datos, pero el resto de la intervención va encaminada en la dirección contraria:

(2) Usted es de Jaén, y todos los nacidos en Jaén, por el solo hecho de que tienen un olivo al lado, saben que las campañas del olivar son campañas partidas, no son en años naturales. (8-10/APC-000146, pág. 10)

A través de un silogismo claro y simple la hablante contradice su argumentación anterior y sugiere que no se trata de una mala lectura de los datos sino de una manipulación malintencionada de los mismos, lo que supone un claro ataque, no a la capacidad intelectual del oponente, sino más bien a su integridad como político, al atribuirle indirectamente la manipulación de los datos para criticar al Gobierno. En este sentido, la falsa mitigación (Blas Arroyo, 2003) a través del tono integrador y atenuado del principio funciona como un enfatizador en un acto de amenaza posterior. Por tanto, se puede concluir que supone un ataque indirecto e implícito a través de un uso irónico de la atenuación que, a su vez, se puede interpretar como un uso indirecto del rol MD con el fin discursivo del rol DH.

\subsubsection{Atenuante}

En los temas socialmente sensibles como la sanidad o el desempleo, por ejemplo, se aprecia el rol MD orientado hacia el consenso o búsqueda de un terreno común dentro de la discrepancia. En una pregunta oral del pP sobre dependencia el Sr. Armijo, del grupo popular, pregunta cuál es la causa por la que la creación de plazas en centros de estancias nocturnas no se ha realizado a un ritmo adecuado, a lo que la Consejera para la Igualdad y Bienestar Social le contesta:

(3) Consejera: Sr. Armijo, pero si yo puedo coincidir con usted y estar de acuerdo con usted, lo que hace falta es que las familias estén de acuerdo... en esto podemos tener el mismo punto de vista, si yo no le estoy contradiciendo. Lo único que quiero decirle es que plazas hay en este momento que están desocupadas [...] ¿Qué tendremos que hacer, una campaña? Pues a lo mejor tenemos que hacer una campaña. Espero que no venga luego usted aquí y me critique por la campaña $[. .$.$] -esto es una broma-. (8-08/POC-000020, pág. 20)$

En este caso, queda patente la desconfianza de la hablante, quien se sirve de una broma para sugerir que el fin último de su contrincante es la crítica en sí y no aportar soluciones a las cuestiones que se debaten. Sin embargo, su tono 
generalmente cordial se puede justificar dentro de la temática de índole social que se está tratando.

La consejera, con el énfasis en la concordia, consigue un discurso atenuado e integrador con el que rompe la dualidad gobierno-insensible frente a oposiciónsensible que su oponente había marcado en su intervención anterior. En este sentido, la búsqueda de un terreno común previo a un ataque atenuado, en el que la crítica se minimiza y explica como una broma, funciona como un atenuante interesado, orientado a fortalecer indirectamente la imagen de su grupo frente a la imagen del adversario, pues se presenta como grupo dialogante y sensible a cuestiones socialmente delicadas.

Otro ejemplo similar en este sentido es el siguiente en relación a la concertación de Sanidad con empresas privadas de la Consejera de Salud, en contestación a la intervención del Sr. Sánchez Gordillo del grupo andalucista, quien se muestra reacio a este tipo de práctica.

(4) Consejera de Salud: Bueno, yo creo, Sr. Sánchez Gordillo, que de la parte inicial de su exposición yo creo que compartimos todas las personas que estamos en esta Comisión que la sanidad es un..., la salud, no la sanidad, la salud, es un derecho y que, por tanto, los poderes públicos tienen que tener la capacidad de garantizarlo. (8-10/APC-000319, pág. 8)

Después de explicar lo que les une, procede a relatar lo que les separa, aunque este punto de partida está igualmente destinado a favorecer la imagen de su grupo frente al de la oposición. Tras la introducción en (4) la consejera deja patente su crítica, en este caso en relación al escaso fundamento de las reservas del grupo del Sr. Sánchez Gordillo con el tema que les ocupa.

(5) Me gustaría a mí que alguna vez, Sr. Gordillo, se expresaran ustedes con datos. ¿Se refiere a datos de calidad? ¿Es que hay una mayor mortalidad? ¿Es que hay un mayor volumen de negligencia? (pág. 9)

La crítica, en esta ocasión, es sólida y está orientada a minar la imagen positiva del grupo atacado, pues va más allá de la anécdota y de lo incidental. Con la alusión temporal «alguna vez» el comportamiento del grupo oponente se extiende en el tiempo, dando a entender que es una característica inherente del mismo. Es decir, es un grupo cuyos argumentos no están nunca suficientemente fundamentados en datos o hechos, sino más bien, se podría pensar, se deben a cuestiones ideológicas poco realistas, lo que por omisión, se podría entender, contrasta con la actitud de su grupo. 


\subsubsection{Refuerzo del grupo parlamentario del hablante en contraste con el del oponente}

En la interacción entre las consejeras y los miembros de su grupo parlamentario concreto, se observa que este rol se aplica sin reservas, reforzando la imagen de los interlocutores y por ende el del grupo al que ambos pertenecen.

En la comparecencia de la Excma. Sra. Consejera para la Igualdad y Bienestar Social, a fin de informar sobre las unidades de género de la Junta de Andalucía, encontramos los siguientes intercambios:

(6) Consejera Igualdad: Andalucía ha coincidido plenamente en este discurrir de la acción pública en materia de igualdad... no puede ser de otra forma. (8-10/ APC-000689, pág. 10)

(7) Sra. Tomé Rico PSOE: para los socialistas, la igualdad forma parte de nuestro ideario político y cuando hablamos de igualdad, hablamos de igualdad con mayúsculas (pág. 13) [...] pese a quien pese. (pág. 14)

(8) Consejera Igualdad: Sra. Tomé Rico, además de agradecerle la petición de esta comparecencia, donde se demuestra, una vez más, su interés por saber exactamente qué medidas se están desarrollando que hagan posible que esa igualdad que nos reconoce la Constitución... sea efectiva. (pág. 14)

La tensión entre el grupo de la consejera y el de la oposición queda reflejada en el ejemplo (7) donde la hablante añade «pese a quien pese». Es decir, se está dando por sentado que el subgrupo oponente no comparte sus principios. Es más, según ella, contrasta con la «igualdad con mayúsculas», la que se alega defienden ellos. Esta es una clara alusión al principal grupo de la oposición, que no participa en esta comparecencia, lo que no impide que sea objeto de crítica. Se establece un claro contraste entre nosotros y ellos que marca una brecha de \pm autoridad moral.

La consejera, por su parte, despliega todo un abanico de recursos y estrategias discursivas para reforzar la imagen positiva de su interlocutora. Esto se intenta a través de un lenguaje de tipo objetivo (o al menos con apariencia de objetividad) con ausencia de modalidad, con verbos de naturaleza empírica como «demostrar», alusiones a la constancia, «una vez más», que implican coherencia y veracidad, y formulaciones extremas, «saber exactamente». Todo ello contribuye a la creación de una imagen profesional, coherente y capaz de un miembro de su grupo parlamentario, grupo que a su vez recibe indirectamente la autoridad moral que la consejera está otorgando a uno de sus miembros.

A continuación procedemos a comentar brevemente los resultados obtenidos del análisis de la muestra de control masculina. Se aprecia que el rol MD también 
aparece en situaciones similares y con las mismas funciones que en el caso de sus colegas consejeras.

Por ejemplo, en relación a la pregunta oral relativa al servicio de transporte escolar al CEIP Los Molinos, de Vejer de la Frontera, Cádiz, el Sr. García Rodríguez (GP Izquierda Unida Los Verdes) reivindicaba que no había transporte escolar para dicho centro y por ese motivo no había alumnos matriculados en el mismo que lo pudiesen necesitar. La respuesta del Consejero de Educación es la siguiente:

(9) Mire, señor García, vaya por anticipado mi reconocimiento a que usted conoce aquella zona más que yo. Vamos, hasta ahí podíamos llegar. Y me son útiles sus conocimientos y los datos que me aporta [...] Pero nosotros vamos a poner transporte donde haya un niño que lo necesite. No vamos a poner el transporte sin ningún niño [...] No puede usted justificar, porque no es verdad, no es verdad, no tiene usted ahí ninguna razón. En otras muchas cosas la tiene, y se la acepto, pero no en esa. (8-10/POC-000575, pág. 12)

En este caso, el rol puede funcionar como atenuante en un contexto socialmente sensible como es la educación. Después de mostrar un talante dialogante y de reconocer la valía de su interlocutor, el hablante despliega un discurso enfático dirigido a la defensa de su gestión. Este énfasis se puede apreciar, entre otras cosas, en el uso de repeticiones y formulaciones extremas. Por tanto, el patrón es el mismo, MD para establecer un lazo de colaboración y mostrar interés en un tema delicado seguido de una DH para reivindicar la valía del gestor.

Igualmente se han encontrado ejemplos en los que el rol MD sirve como intensificador en un ataque a la imagen del interlocutor. En la comparecencia del señor Ávila Cano, Consejero de Economía, Innovación y Ciencia, a fin de informar sobre las repercusiones del incremento de la factura eléctrica en Andalucía, el consejero comienza su turno de réplica de la siguiente manera tras una intervención plagada de ataques a la imagen por parte del representante del grupo popular Sr. Delgado Bonilla:

(10) Gracias, Presidente y gracias, señor Bonilla, por una intervención mesurada, pero en la que, a costa de hablar del incremento del precio de la energía y de la tarifa, pues yo creo que solamente nos ha faltado quedar como... no sé, como los autores del desastre del barranco del Lobo, ¿no?, me da la impresión. (8-10/ APC-000779, pág. 21)

Una vez más se aprecia un punto de partida que en principio refuerza la imagen positiva del interlocutor, al que se le reconoce un talante mesurado. Sin embargo, se marca un claro contraste con el resto del párrafo, donde se da a entender justamente lo contrario. El uso de la ironía y la hipérbole («el desastre 
del barranco del Lobo») refuerza un ataque a la imagen en una intervención que comenzó de manera bien distinta.

Finalmente, aportaremos un ejemplo en el que uno de los consejeros hace uso del rol MD con uno de los miembros de su partido, de forma genuina, en un intento por mejorar la imagen del grupo en su totalidad.

(11) Consejero: Y muchas gracias, señora Arenal [GP socialista]. Le reitero mi agradecimiento por permitirme poder hablar de este asunto. Que, sin duda, no tiene precedentes desde el punto de vista de la historia de Andalucía [...]. (8-10/apc-000580, pág. 8$)^{8}$

En esta ocasión el consejero agradece explícitamente a la representante del GP socialista la ocasión que le ha dado de poder hablar sobre un proyecto del que el consejero se siente especialmente satisfecho. La gratitud mostrada no tiene demasiado sentido ya que es una comparecencia a petición de su propio partido en un intento por dar voz a una medida exitosa. Por tanto, podríamos considerarlo un mero formalismo orientado a concentrar, de cara a la galería, una estrategia de partido, en una persona en concreto.

\subsection{Rol MS}

Este uso no se ha detectado en el discurso de las consejeras en sí sino en el de sus interlocutores oponentes en referencia a las mismas. Este rol se caracteriza por la falta de madurez personal y/o profesional atribuida a la responsable e incluso por las libertades que se toma el resto del grupo haciendo bromas a su costa. Cosa que la «mascota» acepta con buen humor como parte de su identidad grupal. Sin embargo, en nuestro corpus no se ha detectado semejante actitud por parte de las consejeras quienes, lejos de asimilar de buen grado los comportamientos anteriormente citados por parte de los miembros de los subgrupos oponentes, rebaten y desmontan los argumentos esgrimidos para reforzar su autoridad.

Analizaremos dos ejemplos claros. En el que se expone a continuación, el Sr. Armijo hace un comentario relativo a la reacción de la Consejera de Agricultura y Pesca en relación a sus críticas sobre la Ley del Olivar.

8. Comparecencia del Excmo. Sr. Consejero de Educación, a fin de informar sobre el balance del Plan Mejor Escuela. 
(12) Sr. Armijo: Tal vez Ud. se haya molestado por las banderillas de fuego con respecto al tema de la Ley del Olivar, que es un desastre y que el Consejo Consultivo -se ponga Ud. como se ponga- se la haya echado patas arriba [...] Si yo fuera la Consejera de Agricultura, evidentemente, esto me preocuparía, no sería tan alegre de verbo y, evidentemente, me pondría a trabajar ya sobre... Bueno, cuando somos constructivos, o intentamos ser constructivos también se molestan. (8-10/APC-000146, pág. 12-13)

(13) Consejera: Es que quiero que ustedes lo comprendan. Yo me voy a empeñar en que lo comprendan. Lo que pasa es que seguramente estarán distraídos en otras estrategias, o también en ámbito constructivo. Yo no me molesto, le puedo asegurar porque yo sé de su voluntad. Señor Armijo, de su tono, que le agradezco, siempre constructivo. Podemos no coincidir, pero no me molesta en absoluto. Simplemente es que hay cosas en que ustedes y nosotros no tenemos coincidencia, evidentemente. (pág. 14)

En el ejemplo (12), el hablante ataca la imagen de la consejera en base a una supuesta reacción emocional de la misma. En otras palabras, da a entender que su réplica anterior, en contra de las críticas recibidas, estaba condicionada, no por motivos derivados del desarrollo de la actividad política y los datos intercambiados en el debate, sino porque simplemente ha reaccionado de forma afectiva en un debate en el que esta actitud no es deseable porque repercute negativamente en la valoración de la profesionalidad del hablante. Esta alusión al afecto como arma arrojadiza queda patente en el uso del verbo «molestarse» como única motivación de la réplica.

Tradicionalmente, se ha considerado que la mujer es más emocional que el hombre y esto quedaba reflejado en su lenguaje (Lakoff, 1973), lo que va en contra de su promoción social. En este contexto en particular, la objetividad y la coherencia son valores en alza y el hecho de que una mujer se deje llevar por sus impulsos va en detrimento de su valía profesional.

El uso de la expresión idiomática del mundo taurino «poner las banderillas de fuego» supone un varapalo para la capacidad profesional de la consejera, pues presupone que esta antepone un arranque emocional al razonamiento y templanza esperados en el desempeño de sus funciones. Implica cierta inmadurez no deseable en su posición, al tiempo que el atacante refuerza su propia imagen dando a entender que ha desarmado a la consejera y la ha dejado sin argumentos racionales y objetivos para explicar el desempeño de sus funciones. Este objetivo se apuntilla con la usurpación del rol asignado a la Sra. Aguilera, «si yo fuera la Consejera de Agricultura [...]».

Este ataque a la capacidad profesional de la consejera se responde reforzando su valía profesional. Esta niega de forma explícita, hasta en dos ocasiones, que se haya molestado, utilizando en la segunda ocasión una formulación 
extrema para recalcarlo. Con esto defiende que sus argumentos están basados en hechos y no en emociones. La defensa de la objetividad de la hablante también se lleva a cabo de forma implícita a través de un discurso en el que se refuerza la imagen positiva del oponente con alusiones directas a su persona: «Señor Armijo, de su tono, que le agradezco, siempre constructivo». Esto puede parecer contradictorio, pues la consejera está respondiendo a un ataque a su imagen por parte de su interlocutor. La consejera no habla sobre su objetividad sino que actúa objetivamente, reconociendo la valía del contrario y encontrando un terreno común sobre el que fundamentar sus diferencias de forma neutral, que es justo lo contrario de lo que haría en caso de ser una persona dominada por sus emociones. Es decir, demuestra a su oponente y a su audiencia que sus acusaciones no se corresponden con la realidad. Esto se hace en paralelo a un ataque al grupo parlamentario al que el oponente representa: «estarán distraídos en otras estrategias», presuponiendo de forma indirecta que la motivación de las alusiones a su falta de profesionalidad no es otra que el deterioro de la imagen del Gobierno con fines puramente partidistas y poco profesionales; recuperando el equilibrio e invirtiendo la balanza a su favor y evaluando negativamente la moralidad del grupo parlamentario popular.

En el segundo ejemplo analizamos la intervención del Sr. Loaiza García (grupo parlamentario popular); en relación al apoyo a la pesca tradicional del atún rojo podemos leer:

(14) El peso específico del Gobierno de Andalucía, en este caso, no se ha visto representado o no ha tenido la fuerza suficiente como la han tenido los catalanes [...] ¿era solo de su consejería o porque era mejor no molestar al Ministerio? [...] Con esto yo sí que tengo que decirle, señora consejera, que no pongo en duda el esfuerzo que su Consejería ha hecho para defender el sector, que yo creo que no se vio recompensado, que no se vio apoyado por su Gobierno en Madrid, por el Gobierno de su partido, y que, en ese sentido, su Consejería tiene que hacer un mayor esfuerzo a nivel interno, a nivel interno $[\ldots]$ ¿o vamos a verlas venir y empezar a trabajar otra vez en diciembre o enero? (8-10/APC-000236, pág. 11-12)

A lo que la consejera responde:

(15) Ese era nuestro compromiso... y que no se perdiera ni un solo empleo, ante las dificultades que tenían. Y eso hemos conseguido, eso lo hemos conseguido [...] no hemos dejado en ningún momento de seguir trabajando [...] yo creo, Sr. Loaiza, que a lo mejor tiene alguna confusión. Me parece normal, esto es realmente un poquito complejo a veces. (pág. 15) 
En este caso, el Sr. Loaiza ataca la imagen de la consejera poniendo en duda el peso de la misma dentro de su partido. Se ataca su capacidad profesional denigrando su autoridad dentro del subgrupo al que pertenece, «no ha tenido la fuerza suficiente». Esto se enfatiza a través de la comparación de resultados de su comunidad con la de otra comunidad autónoma y a través del uso de la ironía, «era mejor no molestar al ministerio». El verbo «molestar» en este contexto conlleva una evaluación negativa de la profesionalidad de la consejera, pues se puede interpretar que estar a bien con su partido para ella es más importante que cumplir con sus obligaciones a la cabeza de la Consejería de Agricultura y Pesca y defender los intereses de Andalucía. Su valía profesional queda en entredicho al asignarle el rol MS dentro de su partido, pues según el representante del principal grupo de la oposición la consejera no ha sido tomada en serio y ella lo acepta al no querer «molestar».

Sin embargo, no se puede decir que la consejera se deje encasillar en este rol dentro del debate, pues en su réplica no tiene ningún inconveniente en «molestar» a su adversario con un claro ataque a su imagen, indicando que estaba equivocado en su crítica.

En primer lugar encontramos claros rasgos correspondientes al rol DH (formulaciones extremas; «ni un solo empleo», «en ningún momento») en los que defiende su capacidad profesional para a continuación pasar a atacar la imagen de su adversario. El patrón es, primero defensa y luego ataque, ataque que se hace en los mismos términos de la crítica recibida. La alusión a la confusión del oponente junto con el uso del diminutivo en la frase «esto es realmente un poquito complejo a veces», pone en tela de juicio la capacidad intelectual del oponente, de manera que la hablante adquiere mayor autoridad al verse en la postura de tener que explicárselo para que lo entienda. No se ha descrito el rol de maestra pero definitivamente bien cabría en este ejemplo. La mayor cualidad de este rol sería el contraste maestra/sabiduría/autoridad frente a estudiante/ ignorancia/inmadurez.

En el caso de los consejeros no se ha apreciado en la muestra ningún ataque directo a la persona en este sentido, pero sí que se ha podido observar el leitmotiv de la indefensión de Andalucía frente el Gobierno central y la necesidad de que el Gobierno de Andalucía defienda adecuadamente los intereses de la comunidad.

(16) Sr. Vaquero del Pozo (gP Izquierda Unida Los Verdes): Y entonces, ¿no se habla de eso aquí en Andalucía? ¿Cómo van a quedar nuestras cajas? [...] En Andalucía, ¿cómo está esa situación de las cajas andaluzas, de las que el Gobierno andaluz todavía tiene tutela por ley, pero que se la van a quitar ahora mismo? ¿No se habla también de eso? Porque, efectivamente, tendrá algo que decir el Gobierno andaluz [...] Las políticas del estado son para todos, pero, en este caso concreto, en esto concretamente, ahí el Gobierno andaluz tiene cosas 
que decir, y yo no le he oido a usted hablar de todo esto. ${ }^{9}$ (8-10/APC-000538, pág. 11)

A lo que el consejero responde:

(17) Vamos a tener que interpretar todo lo que está pasando con el sistema financiero español y, en particular, con las cajas de ahorro. No en clave andaluza, que también, que me parece bien, pero, no podemos olvidar el marco general. Y, el marco general, lo ha dicho usted antes, lo ha dicho creo que perfectamente. Dice: «Las cajas de ahorro»-le he tomado nota- «van a acudir a los mercados financieros y no van a conseguirlo». Pues, mire usted, eso lo explica todo, eso lo explica todo. Porque es que las cajas de ahorro no tienen el dinero en huertos, ni en una máquina, ni en un saco. Tienen que acudir a los mercados financieros para poder desarrollar su función. (pág.15)

El Sr. Vaquero del Pozo acusa en cierto sentido al consejero de no dar la importancia que merece a la situación de las cajas andaluzas al no proporcionarles un espacio propio en su comparecencia. El consejero responde en global aunque sin quitar importancia al argumento de su interlocutor. En este caso, y tal vez porque su valía profesional no ha sido atacada tan abiertamente como en el caso de la consejera, observamos una reacción en clave de MD, en un esfuerzo por aunar criterios. Se alude a una cita directa del interlocutor con una aclaración explícita de que se ha tomado nota y se da la razón al oponente en un tema tangencial (cómo funciona el sistema de financiación) para justificar una acción más general (el porqué de la preferencia de una visión global/nacional/internacional frente a un enfoque mucho más sectario/autonómico del problema de las cajas). Es decir, el consejero se apodera de las palabras de su interlocutor y las usa como mejor le conviene para justificarse a sí mismo dentro de una ilusión de acuerdo.

\section{Conclusión}

Nos hemos centrado en el uso de los roles trampa MD y MS dentro del Parlamento Andaluz y, aunque se han observado ejemplos claros de estos usos, no se puede concluir que ello suponga una feminización en el lenguaje de las consejeras. Lejos de aportar una nota discordante y romper con la tónica discursiva general de la CdP en la que tienen lugar, estas estrategias se acomodan al estilo marcadamente agresivo (masculino) que domina el foro en el que se debate y al que claramente las líderes del grupo se han adaptado haciéndolo suyo. Los

9. El énfasis es mío. 
roles DH y SD a nivel lingüístico han sido descartados por su escaso interés en el corpus estudiado. En el caso de DH se trata de un comportamiento político, pues el estilo agresivo y directo típico de este rol es el estilo común del foro de nuestro estudio (Brenes, 2012). El rol SD se ha descartado igualmente por la idiosincrasia del marco, pues los comportamientos sexistas son duramente reprendidos y no hemos encontrado ningún ejemplo en este sentido.

El estudio se ha llevado a cabo desde la perspectiva de la cortesía, observando que los citados roles funcionan como recursos discursivos estratégicos relacionados con la defensa y el ataque de la imagen personal y profesional, así como de los diferentes partidos políticos que forman parte de lo que podemos considerar una comunidad de práctica.

Igualmente, se ha analizado una muestra de control donde participan consejeros (hombres) para comprobar si estos roles son típicamente femeninos o si por el contrario se trata de una serie de estrategias discursivas que usan ambos sexos y, por tanto, carecerían de interés a la hora de realizar un análisis discursivo desde la perspectiva de género. Los usos concretos que se han detectado son los siguientes:

Rol MD:

- Como intensificador en un ataque a la imagen del oponente. La atenuación propia del rol MD sirve de contrapunto a un ataque posterior, creando un contraste que aporta un matiz irónico a dicha atenuación. En este sentido se podría considerar que este rol, con dicho fin, supone un uso indirecto del rol $\mathrm{DH}$, pues se hace un uso lingüístico de un rol determinado con un efecto discursivo propio de otro.

- Como atenuante en los ataques a la imagen propios del foro en el que se debate. Este uso se ha detectado cuando se debaten temáticas con un trasfondo social sensible. Se habla abiertamente de las diferencias entre partidos pero se intenta encontrar un punto de encuentro en la sensibilidad a los problemas tratados, que posiciona al grupo del hablante a un nivel moral similar al de los contrincantes a pesar de no coincidir en todos los puntos que se tratan. Aquí la atenuación tiene un claro fin estratégico de refuerzo de la propia imagen de grupo.

- Como refuerzo del grupo parlamentario del hablante en contraste con el del oponente. Solo en este caso el uso del rol es genuino, sin ninguna contrapartida que contradiga lo que se ha dado a entender anteriormente. Generalmente, se encuentra en alusiones a miembros del propio partido y si el partido oponente es mencionado de alguna manera siempre es en detrimento del mismo. 
Rol MS:

- El rol MS no se detecta en el lenguaje de las consejeras sino en la forma en que sus oponentes se dirigen a ellas. Los ejemplos analizados hacen referencia a un comportamiento afectivo inapropiado y a la ausencia total de autoridad de la consejera dentro de su propio partido y merma así la valía profesional de la misma. Muy contrariamente a lo que haría una «mascota», las consejeras defienden su capacidad profesional y atacan abierta y directamente la imagen del contrario mostrándose como profesionales neutrales y responsables, dando a entender una actitud malintencionada por parte de sus oponentes. Esta actitud se corresponde con el rol de dama de hierro, por lo que podemos concluir que el rol de dama de hierro aparece de forma consistente como respuesta o reacción de las consejeras cuando se les intenta asignar el rol de mascota, lo que puede ser considerado un ataque a su imagen al no corresponderse con la típica imagen de líder esperada dentro del foro estudiado.

Por tanto, el uso a nivel lingüístico de los roles analizados aporta cierto colorido a la tónica discursiva general del foro donde se hace uso de ellos, sin que ello suponga una ruptura con el lenguaje propio del entorno. Sin embargo, no podemos negar que, en ciertos casos, como cuando actúan como intensificadores o atenuantes en un ataque a la imagen del oponente, se crea un estilo indirecto y sutil alejado de los ataques directos a la imagen del oponente típicos del Parlamento Andaluz.

El hecho de que este tipo de lenguaje se encuentre igualmente en las filas masculinas de este foro nos da a entender que no se trata de un estilo propiamente femenino, aunque no descartamos que estos usos puedan tener matices diferentes por parte de hombres y mujeres. Lo que se ha podido constatar en este estudio es que ambos sexos los usan, lo cual nos hace pensar que los roles trampa como unidad de análisis posiblemente funcionen mejor en estudios sociológicos que en estudios lingüísticos.

\section{Referencias bibliográficas}

BAXter, J. (2012): «Women of the Corporation: A Sociolinguistic Perspective of Senior Women's Leadership Language in the UK», Journal of Sociolinguistics, 16 (1): 81-107.

Blas Arroyo, J. L. (2003): «Perdóneme que se lo diga, pero vuelve usted a faltar a la verdad, señor González: Form and Function of Political Verbal 
Behaviour in Face-to-face Spanish Political Debates», Discourse and Society, 14: 395-423.

Brenes, E. (2012): «Género, Discurso Político y Descortesía Verbal. Análisis de la Influencia de la Variante Sexo en el Parlamento Andaluz», Discurso y Sociedad, 26 (1-2): 59-77.

Cameron, D. (1985): Feminism and Linguistic Theory, London, Macmillan Press.

- (1990): The Feminist Critique of Language. A Reader, London, Routledge.

- (2006): «Theorising the Female Voice in Public Contexts», en J. BAXTER (ed.) (2006): Speaking Out in Public Contexts, Basingstoke, Palgrave.

Christie, C. (2002): «Politeness and the Linguistic Construction of Gender in Parliament: An Analysis of Transgressions and Apology Behaviour» in Sheffield Hallam Working Papers on the Web: Linguistic Politeness and Context. http://www.shu.ac.uk/wpw/politeness/christie.htm

CoAtes, J. (1993): Woman, Men and Language: A Sociolinguistic Account of Gender Differences in Language, Londres, Longman.

ECKerT, P.; S. MCConnell-Ginet (1992): «Think Practically and Look Locally: Language and Gender as Community-based Practice», Annual Review of Anthropology, 21: 461-90.

Holmes, J. (2006): Gendered Talk at Work, Oxford, Blackwell.

KANTER, R. (1993 [1977]): Men and Women of the Corporation, $2^{\mathrm{a}}$ ed., Nueva York, Basic Books.

Kramarae, C. (1981): Women and Men Speaking. Frameworks for Analysis, Rowley, Newbury House Publishers.

LAKOFF, R. (1973): «Language and Woman's Place», Language in Society, 2 (1): 45-79.

- (1975): Language and Woman's Place, New York, Harper and Row Publishers.

Lave, J.; E. Wenger (1991): Situated Learning: Legitimate Peripheral Participation, Cambridge New York, Cambridge University Press.

Litosseliti, L.; J. Sunderland, J. (eds.) (2002): «Discourse Analysis And Gender Identity», Discourse Approaches To Politics, Society And Culture, Vol. 2, Amsterdam, Benjamins.

Lozano, I. (1995): Lenguaje Femenino, Lenguaje Masculino. ¿Condiciona nuestro sexo la forma de hablar?, Madrid, Minerva Ediciones.

Priora C.; Brannen, M. (2009): «"Between a Rock and a Hard Place": Exploring Women's Experiences of Participation and Progress in Managerial Careers», Equal Opportunities International, 28: 378-397.

SCHNURR, S. (2009): Leadership Discourse at Work: Interactions of Humour, Gender and Workplace Culture, Basingstoke, Palgrave. 
TAnnen, D. (1990): You Just Don 't Understand: Women and Men in Conversation, New York, Ballantine Books.

- (1994): Gender and Discourse, Oxford, OuP.

WatTs, R. (1992): «Linguistic Politeness and Politic Verbal Behaviour: Reconsidering Claims for Universality» en R. WATts; I. SACHIKo; K. EнLicH (eds.) (1992): Politeness in Language: Studies in its History, Theory and Practice, Berlin y Nueva York, Mouton de Gruyter, 43-70.

Wenger, E. (1998): Communities of Practice, Cambridge, Cambridge University Press. 